\title{
Factors associated with concentrations of select cytokine and acute phase proteins in dairy cows with naturally occurring clinical mastitis
}

\author{
J. R. Wenz, ${ }^{* 1}$ L. K. Fox, ${ }^{*}$ F. J. Muller, $†$ M. Rinaldi, $\ddagger^{2}$ R. Zeng,§ and D. D. Bannerman $\ddagger^{3}$ \\ ${ }^{*}$ Field Disease Investigation Unit, Department of Clinical Sciences, Washington State University, Pullman 99164 \\ †Ag Health Laboratories, Sunnyside, WA 98944 \\ łBovine Functional Genomics Laboratory, Beltsville Agricultural Research Center, Agricultural Research Service, USDA, Beltsville, MD 20705 \\ $\S$ Department of Animal and Avian Sciences, University of Maryland, College Park 20742
}

\begin{abstract}
The objective of the current observational study was to determine the potential associations between cow factors, clinical mastitis (CM) etiology, and concentrations of select acute phase proteins and cytokines in milk from affected quarters of cows with CM. Cows with CM ( $\mathrm{n}=197)$ were grouped based on systemic disease severity, milk culture result, parity, days in milk (DIM), previous CM occurrence, and season of the year when CM occurred. Concentrations of lipopolysaccharide-binding protein (LBP), haptoglobin $(\mathrm{Hp})$, BSA, IFN- $\gamma$, tumor necrosis factor- $\alpha$ (TNF- $\alpha)$, IL-1 $\beta$, IL-8, IL-10, IL-12, transforming growth factor (TGF)- $\alpha$, and TGF- $\beta$ and activity of lactate dehydrogenase (LDH) were evaluated. Differences in the least squares means $\log _{10}$ transformed concentrations of these proteins were compared using multiple linear regression mixed models. The milk concentrations of LBP, Hp, IL-1 $\beta$, IL-10, and IL-12, and activity of LDH in milk were higher in cows with moderate to severe versus mild systemic disease. The concentrations of Hp, BSA, IL-1 $\beta$, and IL10 in milk were higher in cows with a gram-negative versus gram-positive milk culture result. Season of the year when CM occurred was associated with the concentration of all proteins evaluated except for IL-1 $\beta$ and IL-12. Concentrations were higher in the winter versus summer except for Hp and TGF- $\beta$, for which the opposite was true. Concentrations of LBP, IL-10, and IL-12, and LDH activity in milk were associated with DIM group. Except for LBP, these proteins were lower in cows with $\mathrm{CM}$ during the first 60 DIM versus those in mid or later lactation. Interferon- $\gamma, \mathrm{TNF}-\alpha$, and IL- 8 were undetectable in 67,31 , and $20 \%$ of samples,
\end{abstract}

\footnotetext{
Received October 12, 2009.

Accepted March 1, 2010.

${ }^{1}$ Corresponding author: jrwenz@vetmed.wsu.edu

${ }^{2}$ Current affiliation: Department of Veterinary Virology, Parasitology and Immunology, Faculty of Veterinary Medicine, Ghent University,

${ }^{3}$ Current affiliation: US Department of Veterans Affairs, Office of Research Oversight, Washington, DC 20420.
} Belgium. respectively. Detection of IFN- $\gamma$ and IL-8 was associated with season, and detection of TNF- $\alpha$ and IL- 8 was associated with systemic disease severity. The current study provides the most comprehensive report of milk concentrations of innate immune response proteins in cows with naturally occurring CM and identifies factors that potentially influence those concentrations. Further investigation into the seasonal variation of cytokine production and its potential effect on the outcome of $\mathrm{CM}$ is warranted. Furthermore, the results of this study provide useful data for planning future studies examining the role of the innate immune response in CM.

Key words: cytokine, acute phase protein, clinical mastitis, dairy cow

\section{INTRODUCTION}

Clinical mastitis (CM) continues to be the most common and costly infectious disease of dairy cattle (Seegers et al., 2003; USDA, 2007). The pathogenesis of IMI and manifestation as CM is determined by virulence factors of the bacterial pathogen (Hornef et al., 2002) as well as cow factors, particularly the immune response of the cow (Burvenich et al., 2003). The innate immune response is the first line of active defense once pathogens have entered the mammary gland, and it occurs at the earliest stages of infection (Uthaisangsook et al., 2002). This response is typified by production of cytokines at the site of infection and production of acute phase proteins (APP) predominantly in the liver. Bovine mammary epithelial cells and leukocytes produce cytokines that mediate the inflammatory response both locally and systemically through multiple and often redundant functions (Taniguchi, 1995). It has been noted that a fine balance exists between the beneficial and deleterious effects of cytokines on the host, and that this balance is influenced by the duration, amount, and location of cytokine expression (Bannerman, 2009).

Numerous studies have evaluated cytokine and APP concentrations in the milk and blood of cows to better understand the role of these proteins in the pathogenesis of CM. Such knowledge could lead to potential thera- 
peutic applications and the identification of biomarkers for the diagnosis and prognosis of CM episodes. Much of our current understanding of the innate immune response during CM is based on experimental infection model studies, although some studies have evaluated cows with naturally occurring CM (Alluwaimi, 2004; Rainard and Riollet, 2006; Bannerman, 2009). Experimental model studies allow evaluation of the response over time to different pathogens and have advantages of a known inoculum size and duration of infection; however, they have typically consisted of a small number of experimental units (5-10 cows). The small sample size of these studies has precluded evaluation of the association of factors such as parity, stage of lactation, previous CM occurrence, and disease severity on the levels of innate immune response proteins in the milk of cows during CM. Studies involving naturally occurring CM have been limited and generally focused on only a few APP (Chagunda et al., 2006; Lai et al., 2009; Zeng et al., 2009) or cytokines (Ohtsuka et al., 2001; Hisaeda et al., 2001), and most studies did not evaluate the influence of such factors on the concentrations of these proteins. Furthermore, these studies focused on coliform mastitis or did not differentiate CM etiology. Ohtsuka et al. (2001) identified differences in tumor necrosis factor- $\alpha$ (TNF- $\alpha)$ and IL-1 concentrations at CM identification based on severity of clinical signs.

The purpose of the current observational study was to characterize the innate immune response of dairy cattle during naturally occurring CM by evaluating the milk concentrations of LPS-binding protein (LBP), haptoglobin $(\mathbf{H p})$, and select cytokines. The objective was to determine potential associations between cow factors (systemic disease severity, DIM, parity, and previous CM occurrence), CM etiology, and concentrations of select APP and cytokines. Such information should prove useful when planning studies of the innate immune response during $\mathrm{CM}$ in dairy cattle and the potential use of these proteins as therapeutics or markers for diagnosis and prognosis of CM episodes.

\section{MATERIALS AND METHODS}

\section{Study Herd}

Dairy cows from a single commercial dairy in southcentral Washington State that developed CM from June 2007 to May 2008 were eligible for inclusion in the study. During the study period, the herd had an arithmetic mean bulk tank SCC $<280,000$ cells $/ \mathrm{mL}$. All cows and periparturient heifers were vaccinated with a gram-negative core antigen bacterin (Upjohn J-5 Bacterin, Pfizer Animal Health, New York, NY) according to label directions. Cows were milked 3 times daily in a double- 25 parallel parlor, except for cows in the hospital pen, which were milked twice daily. Cows were fed a TMR and housed in freestall barns bedded with dry manure or in open dry lots with permanent shade structures.

\section{Inclusion Criteria and Data Collection}

Farm personnel identified cows with $\mathrm{CM}$ based on the presence of abnormal milk, mammary gland inflammation, or both. Milk was considered abnormal based on the presence of flakes or clots or by changes in color or viscosity. These observations were made at milking time, and cows with abnormalities were moved to the hospital pen. Cows with CM were evaluated by study personnel at the next a.m. or p.m. hospital pen milking before the initiation of therapy. Cows eligible for enrollment were those with $\mathrm{CM}$ in a single quarter and no history of CM for $30 \mathrm{~d}$ prior. Parity, DIM, rectal temperature, and rumen contraction rate were recorded. Episodes of $\mathrm{CM}$ in the current or previous lactations occurring $>30 \mathrm{~d}$ before enrollment were identified using herd health records and recorded for each cow. Cows were grouped as having or not having a previous CM episode. Hydration status was estimated based on degree of enophthalmos and scored as 0 (none), 1 (mild), 2 (moderate), or 3 (marked). Attitude was classified based on signs of depression (observing the cow's head and ear carriage and response to stimuli) as none, mild, or marked.

\section{Severity Classification}

A systemic severity score of mild, moderate, or severe was assigned to cows with CM based on rectal temperature, hydration status, rumen contraction rate, and attitude as described previously (Wenz et al., 2001a).

\section{Sample Collection}

Milk samples were collected from the affected quarter of cows 1 to $12 \mathrm{~h}$ after identification of CM, just before their next milking. Two 10-mL samples of secretions from affected mammary glands were collected aseptically: one for bacterial culture and a second for determination of APP, BSA, and cytokine concentrations. Teat ends were disinfected with $70 \%$ isopropyl alcohol and 2 streams of secretion were removed from the affected quarter before sample collection. All samples were collected before initiation of therapy and were immediately placed on ice for transport to the laboratory where they were stored at $-70^{\circ} \mathrm{C}$.

\section{Bacteriologic Culture of Milk}

A $100-\mu \mathrm{L}$ sample of milk was plated on $5 \%$ bovine blood agar and MacConkey agar plates. Presumptive 
identification of gram-negative coliform bacteria was based on colony morphology, growth on MacConkey agar, and a positive $\mathrm{KOH}$ test. Presumptive identification of streptococci was based on colony morphology on blood agar and a negative catalase test. Coagulasenegative Staphylococcus spp. were identified based on colony morphology, lack of $\beta$-hemolysis on blood agar, and a negative coagulase test. Presumptive coliforms and streptococci were speciated using the API20E and the API20 Strep miniaturized microbial biochemical identification kits (bioMérieux Inc., Durham, NC). Gram-negative bacteria were grouped as Escherichia coli or gram-negative, non- $E$. coli (COLIF). Streptococcal organisms other than Strep. agalactiae were grouped as environmental streptococci (ENS). Intramammary infection by a specific pathogen was diagnosed if samples contained $\geq 10 \mathrm{cfu} / \mathrm{mL}$ in pure growth. Plates with $\geq 3$ different organisms were considered contaminated. Cows with milk samples from which no bacteria grew on aerobic culture were grouped as bacteriologically negative $(\mathbf{B N})$.

\section{Whey Preparation}

For the preparation of whey, milk samples were centrifuged at $44,000 \times \mathrm{g}$ at $4^{\circ} \mathrm{C}$ for $30 \mathrm{~min}$ and the fat layer removed with a spatula. The skim milk was decanted into a clean tube and centrifuged for $30 \mathrm{~min}$ as above and the translucent supernatant collected and stored at $-70^{\circ} \mathrm{C}$.

\section{ELISA}

Samples were evaluated by ELISA for IFN- $\gamma$, IL-8, IL-10, IL-12, transforming growth factor (TGF)- $\alpha$, and TGF- $\beta 1$, as described previously (Bannerman et al., 2003, 2004, 2005). Concentrations of BSA were determined using a commercially available ELISA kit (Bethyl Laboratories Inc., Montgomery, TX) as described previously (Bannerman et al., 2003), with the exception that wells were coated with $10 \mu \mathrm{g} / \mathrm{mL}$ of sheep anti-bovine BSA antibodies for $1 \mathrm{~h}$ at room temperature instead of overnight at $4^{\circ} \mathrm{C}$. Concentration of LBP was assayed using a commercially available ELISA kit (Cell Sciences Inc., Canton, MA) that recognizes both human and bovine LBP, as described previously (Bannerman et al., 2003). Milk concentration of LBP was determined by extrapolation from known amounts of serially diluted recombinant human LBP (R\&D Systems Inc., Minneapolis, MN), which was assayed along with the samples. Samples with absorbance readings that exceeded those of the highest standard were further diluted and reanalyzed. Milk TNF- $\alpha$ concentrations were assayed using a previously described ELISA
(Bannerman et al., 2004) and extrapolating from a standard curve generated by serially diluting reference plasma containing known amounts of bovine TNF- $\alpha$ (generously provided by T. H. Elsasser, Bovine Functional Genomics Laboratory, Beltsville Agricultural Research Center, USDA-ARS, Beltsville, MD). Milk IL-1 $\beta$ concentrations were determined by ELISA as described previously (Bannerman et al., 2004) with the exception that $10 \mu \mathrm{g} / \mathrm{mL}$ of rabbit anti-bovine IL-1 $\beta$ antibodies (Serotec Ltd., Oxford, UK) were used as the detection antibodies instead of 1:500 diluted rabbit anti-ovine IL-1 $\beta$ sera. Concentrations of IL-1 $\beta$ were determined in the current study by extrapolation from a standard curve generated by serially diluting recombinant bovine IL-1 $\beta$ (Pierce Biotechnology Inc., Rockford, IL) instead of recombinant ovine IL-1 $\beta$ as originally described.

Haptoglobin concentrations were determined with a commercially available ELISA kit (Alpco Diagnostics, Salem, NH) according to the manufacturer's instructions. Samples were analyzed with a microplate reader (Bio-Tek Instruments Inc., Winooski, VT) at a wavelength of $450 \mathrm{~nm}$ and a correction wavelength of $565 \mathrm{~nm}$. The concentrations of $\mathrm{Hp}$ in the samples were calculated by extrapolation from a standard curve of known amounts of bovine Hp generated by serially diluting the bovine Hp standard included in the commercial ELISA kit.

\section{Assay for Lactate Dehydrogenase}

For the determination of lactate dehydrogenase (LDH) activity, the whey fractions of collected milk samples were diluted 1:3 in PBS containing 1\% BSA and assayed as described previously (Lauzon et al., 2006) using a commercially available kit (CytoTox 96 Non-Radioactive Cytotoxicity Assay, Promega Corp., Madison, WI).

\section{Statistical Analysis}

For analysis, cows were grouped as first, second, or third and greater parity and by DIM group as early (1 to $60 \mathrm{DIM})$, mid (61 to 150), and late (>150 DIM). Cows were also grouped by season of the year during which CM occurred as March to May (spring), June to August (summer), September to November (fall), and December to February (winter). Cows were grouped based on the Gram staining characteristics of the milk culture isolate (Gram status) or by milk culture bacterial isolate (Cult) as described above. Cows with a rectal temperature $>39.3^{\circ} \mathrm{C}\left(102.7^{\circ} \mathrm{F}\right)$ were defined as having fever and those with an absence of rumen contractions during 2 min of auscultation as having rumen atony. Cows were grouped by systemic disease severity 
as mild or moderate to severe for analysis. Data from moderate and severe groups were combined given the low number of cows in the severe group and the similarity in median parity, DIM, and percentage of cows exhibiting the clinical signs evaluated.

The percentage of cows in the Gram status or Cult groups with moderate to severe systemic disease, percentage with a previous CM episode, and percentage exhibiting clinical signs by systemic severity group were compared by a Chi-squared test with an adjustment for multiple comparisons using the FREQ procedure (SAS version 9.2., SAS Institute, Cary, NC) and the SAS macro compprop (Elliott and Reisch, 2006). Median parity, DIM, and protein concentrations were compared between groups with a Wilcoxon rank sum test using the NPAR1WAY procedure (SAS version 9.2., SAS Institute). Visual inspection of the normal probability plots for LBP, Hp, BSA, and cytokine residuals indicated nonnormal distributions; therefore, the data were $\log _{10}$ transformed before analysis. The concentrations of TNF- $\alpha$, IFN- $\gamma$, and IL- 8 were below the level of detection (recorded as zero) in $\geq 20 \%$ of samples, and $\log _{10}$ transformation failed to normalize the data. Therefore, multiple logistic regression models with backward elimination were created for these variables using the LOGISTIC procedure (SAS version 9.2., SAS Institute) to determine the associations between detection of each of these cytokines with the factors evaluated. Differences in the least squares means of the $\log _{10}$ concentrations of LBP, Hp, BSA, and the remaining cytokines were compared by mixed multiple linear regression using the MIXED procedure (SAS version 9.2., SAS Institute). All models included systemic disease severity, previous CM occurrence, parity group, DIM group, season, and Gram status or Cult as independent variables. Significant differences, $\alpha<0.05$, among 3 or more group means were identified by specifying ADJUST $=$ SIMULATE in the LSMEANS statement to control for the family-wise error rate when comparing groups with unequal sample size. Mean $\log _{10}$ concentrations were back transformed to the original scale and reported as the geometric mean and 95\% CI (Bland and Altman, 1996). Cows with a BN milk culture result were excluded from all models. Values of $P<0.05$ were considered significant for all statistical tests and a tendency toward association declared for values of $P$ $>0.05$ but $<0.10$.

\section{RESULTS}

During the study period, the incidence rate of $\mathrm{CM}$ in the herd was 4.8 cases per 100 cow-months at risk and ranged from a low of 3.8 in August 2007 to a high of 7.2 in December 2007. Approximately 60\% of CM recorded during the study period represented the first episode of the cow's current lactation, and $10 \%$ of cases involved multiple quarters. A total of 201 cows with CM in a single quarter were enrolled in the study. Three cows were removed because they had a previous CM episode in the same quarter within $30 \mathrm{~d}$ of the episode of enrollment. Another cow missing severity score data was removed, resulting in 197 cows with $\mathrm{CM}$ included in the study, which represented $13 \%$ of recorded CM in the herd during the study period. The majority of the $87 \%$ of recorded CM cases were not sampled because study personnel were not available to sample every day during the study period. Cows with a BN milk culture result $(\mathrm{n}=50)$ were excluded from mixed multiple linear regression and multiple logistic regression analyses, resulting in 147 cows with CM contributing to these models. The CM episode of enrollment was the first of the lactation for $74 \%$ of cows in the study. There were 26, 47, and 74 cows in the first, second, and third and greater parity groups, respectively.

\section{Bacteriologic Culture of Milk and Previous CM History}

The most prevalent pathogen isolated on aerobic milk culture was E. coli, followed by ENS, COLIF, and CNS (Table 1). Milk culture was bacteriologically negative for 50 (25\%) of cows with CM and these cases were excluded from further analysis. No difference in median parity was observed between cows grouped by Gram status $(P=0.315)$ or Cult $(P=0.157$; Table 1$)$. Median DIM was not different between cows grouped by Gram status $(P=0.094)$ or Cult $(P=0.068$; Table $1)$. Moderate to severe systemic signs associated with CM were most commonly observed in cows with $E$. coli CM (52\%); however, no differences were observed between cows grouped by Gram status $(P=0.291)$ or Cult $(P=0.210 ;$ Table 1$)$. Thirty-one percent $(\mathrm{n}=61)$ of all cows in the study had a previous CM episode in the current or previous lactation that was $>30 \mathrm{~d}$ before the episode of enrollment. There were no differences in the percentage of cows with a previous CM episode when cows were grouped by Gram status $(P=0.759)$ or Cult $(P=0.923$; Table 1$)$.

\section{Severity Classification}

Overall, 61,38 , and $8 \%$ of cows were classified as having mild, moderate, and severe systemic disease, respectively (Table 2). No differences in the median parity, DIM, or percentage with fever, atony, dehydration, or signs of depression were observed between moderate and severe systemic disease groups (Table 2); therefore, moderate and severe groups were combined 
Table 1. The number (n) and percentage of cows with clinical mastitis (CM), median parity, DIM and percentage of cows with moderate to severe systemic signs (MS) at enrollment, and number (n) and percentage with a previous clinical mastitis episode in the current or previous lactation (PMAST) by milk culture isolate $^{1}$

\begin{tabular}{|c|c|c|c|c|c|}
\hline Milk culture isolate ${ }^{2}$ & $\begin{array}{c}\mathrm{CM}, \\
\mathrm{n}(\%)\end{array}$ & $\begin{array}{l}\text { Median } \\
\text { parity }\end{array}$ & $\begin{array}{c}\text { Median } \\
\text { DIM }\end{array}$ & $\% \mathrm{MS}$ & $\begin{array}{c}\text { PMAST, } \\
\text { n }(\%)\end{array}$ \\
\hline All & $197(100)$ & 2.0 & 86 & 39 & $61(31)$ \\
\hline Gram-negative & $83(42)$ & 3.0 & 109 & 45 & $24(29)$ \\
\hline E. coli & $57(29)$ & 2.0 & 109 & 51 & $17(30)$ \\
\hline COLIF & $26(13)$ & 3.0 & 103 & 31 & $7(27)$ \\
\hline Gram-positive & $64(35)$ & 2.0 & 86 & 36 & $20(31)$ \\
\hline CNS & $19(10)$ & 2.0 & 64 & 42 & $5(26)$ \\
\hline ENS & $45(23)$ & 2.0 & 91 & 33 & $15(33)$ \\
\hline $\mathrm{BN}$ & $50(25)$ & 2.0 & 50 & 32 & $17(34)$ \\
\hline
\end{tabular}

${ }^{1}$ No differences in median values or proportions were observed between cows grouped by specific milk culture isolate or based on Gram staining characteristics, excluding the BN group.

${ }^{2} \mathrm{COLIF}=$ gram-negative, non- E. coli ENS = environmental Streptococcus spp.; BN = bacteriologically negative.

for further analyses. The percentage of cows exhibiting fever, atony, dehydration, and signs of depression was greater in the moderate to severe group versus the mild group $(P<0.001$; Table 2$)$.

\section{Univariate Statistics for the Measured Concentrations of Innate Immune Response Proteins in Cows with CM Grouped by Severity and Milk Culture Isolate}

The median and mean concentrations of the proteins measured were typically numerically higher in cows with moderate to severe compared with mild disease across all milk culture isolates (Supplemental Table 1; available online at http://www.journalofdairyscience. org/). The large SD and ranges observed in all groups highlight the wide variation in the concentrations of the innate immune response proteins measured between individual cows. For most proteins evaluated, the data were skewed right resulting in mean values being larger than median values (Supplemental Table 1). The percentage of samples with undetectable protein concentrations was high for IFN- $\gamma$, TNF- $\alpha$, and IL- 8 and typically was higher in cows with mild versus moderate to severe systemic disease across all milk culture isolates. In 5 samples the measured BSA concentration was nearly 10-fold higher than the highest concentration observed in the rest of the samples. These data were retained in the data set and their influence was observed in the reported BSA concentrations of the mild ENS, mild COLIF, and moderate to severe E. coli groups (Supplemental Table 1). Removing these values resulted in dramatic reductions in the mean and SD of BSA in these groups (Supplemental Table 1).

\section{LBP Concentration in Milk}

When cows with clinical mastitis were grouped by Gram status, the concentration of LBP in milk was

Table 2. The number (n) and percentage of cows with clinical mastitis (CM) by systemic severity group ${ }^{1}$ and percentage of cows in each group with fever, ${ }^{2}$ rumen atony, ${ }^{3}$ dehydration, and signs of depression (obtunded)

\begin{tabular}{|c|c|c|c|c|c|c|c|}
\hline Severity group & $\begin{array}{c}\text { CM, } \\
\text { n }(\%)\end{array}$ & $\begin{array}{l}\text { Median } \\
\text { parity }\end{array}$ & $\begin{array}{l}\text { Median } \\
\text { DIM }\end{array}$ & $\begin{array}{c}\text { Fever, } \\
\%\end{array}$ & $\begin{array}{c}\text { Atony, } \\
\%\end{array}$ & $\underset{\%}{\text { Dehydrated, }}$ & Obtunded, \\
\hline Mild & $87(59)$ & 3.0 & 88 & $10^{\mathrm{b}} \dagger$ & $5.8^{\mathrm{b}} \dagger$ & $6.9^{\mathrm{b}} \dagger$ & $18^{\mathrm{b}} \dagger$ \\
\hline Moderate & $47(32)$ & 2.0 & 99 & $49^{\mathrm{a}}$ & $28^{\mathrm{a}}$ & $64^{\mathrm{a}}$ & $77^{\mathrm{a}}$ \\
\hline Severe & $13(9)$ & 2.0 & 91 & $85^{\mathrm{a}}$ & $46^{\mathrm{a}}$ & $92^{\mathrm{a}}$ & $77^{\mathrm{a}}$ \\
\hline Moderate to severe & $60(41)$ & 2.0 & 96 & $57 \dagger$ & $32 \dagger$ & $70 \dagger$ & $77 \dagger$ \\
\hline All & $147(100)$ & 3.0 & 92 & 29 & 16 & 33 & 42 \\
\hline
\end{tabular}

${ }^{\mathrm{a}, \mathrm{b}}$ Values for mild, moderate, and severe groups within a column with different superscripts differ $(P<0.050)$.

${ }^{1}$ Severity classification based on rectal temperature, rumen contraction rate, hydration, and attitude as described previously by Wenz et al. (2001a).

${ }^{2}$ Fever defined as rectal temperature $>39.3^{\circ} \mathrm{C}\left(102.7^{\circ} \mathrm{F}\right)$.

${ }^{3}$ Atony defined as absence of rumen contractions during 2 min of auscultation.

†Values for mild versus moderate to severe groups within a column differ $(P<0.001)$. 
Table 3. Geometric least squares means ${ }^{1}$ and the $95 \%$ CI of measures of the innate immune response in milk from the affected quarter of cows with clinical mastitis by systemic severity accounting for Gram staining characteristics of milk culture isolates, parity group, DIM group, previous clinical mastitis occurrence, and season of the year

\begin{tabular}{|c|c|c|c|c|c|c|c|}
\hline$\frac{\text { Variable }^{2}}{\mathrm{LBP}, \mu \mathrm{g} / \mathrm{mL}}$ & \multicolumn{3}{|c|}{ Mild group $(\mathrm{n}=87)$} & \multicolumn{3}{|c|}{ Moderate/severe group $(\mathrm{n}=60)$} & $\frac{P \text {-value }}{0.015}$ \\
\hline $\mathrm{BSA}, \mathrm{mg} / \mathrm{mL}$ & 4.34 & 3.51 & 5.35 & 5.37 & 4.19 & 6.87 & 0.130 \\
\hline 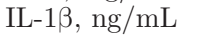 & 2.59 & 2.00 & 3.35 & 4.22 & 3.15 & 5.66 & 0.005 \\
\hline IL-10, U/mL & 16.9 & 11.3 & 25.5 & 48.9 & 30.1 & 79.5 & $<0.001$ \\
\hline TGF- $\beta, \mathrm{ng} / \mathrm{mL}$ & 6.80 & 5.70 & 8.11 & 6.61 & 5.34 & 8.18 & 0.415 \\
\hline $\mathrm{LDH}, \mathrm{U} / \mathrm{L}$ & 1,241 & 973 & 1,585 & 2,135 & 1,604 & 2,842 & 0.014 \\
\hline
\end{tabular}

${ }^{1}$ Mean and CI obtained by taking the antilog of the $\log _{10}$ transformed data.

${ }^{2} \mathrm{LBP}=$ LPS-binding protein; $\mathrm{Hp}=$ haptoglobin; TGF = transforming growth factor; LDH = lactate dehydrogenase.

associated with systemic disease severity, DIM group, and season and tended toward an association with Gram status and previous CM occurrence. Cows with moderate to severe disease had a milk LBP concentration 1.8 times higher than cows with mild disease $(P=0.015$; Table 3$)$. The concentration of LBP in milk tended to be higher in cows with a gram-negative versus gram-positive milk culture result $(P=0.054$; Table 4). Cows with a previous CM episode tended to have a higher concentration of LBP in the milk $(50.8 \mu \mathrm{g} / \mathrm{mL} ; 95 \% \mathrm{CI}: 34,75)$ compared with those that did not $(35.4 \mu \mathrm{g} / \mathrm{mL} ; 95 \% \mathrm{CI}: 28,45 ; P=0.095)$. The concentration of LBP in milk of cows in the late DIM group was approximately half that of cows in the mid $(P=0.047)$ and early $(P=0.028)$ groups (Table $5)$. The concentration of LBP in milk of cows with CM during the summer was approximately half that of those with $\mathrm{CM}$ in the winter $(P=0.027)$ and spring $(P=0.018$; Table 6$)$.

\section{Hp Concentration in Milk}

When cows with clinical mastitis were grouped by Gram status, the concentration of $\mathrm{Hp}$ in milk was associated with systemic disease severity, Gram status, and season and tended toward an association with DIM group. The concentration of $\mathrm{Hp}$ in the moderate to severe group was approximately twice that of the mild group $(P<0.001$; Table 3$)$. The concentration of $\mathrm{Hp}$ in the gram-negative group was approximately twice that of the gram-positive group $(P=0.010$; Table 4$)$. Cows in the mid DIM group tended to have a higher concentration of $\mathrm{Hp}$ in milk compared with those in the early group $(P=0.079$; Table 5$)$. The concentration of Hp was lower in cows with CM during the spring versus those with $\mathrm{CM}$ in the summer $(P<0.001)$ or fall $(P=$ $0.015)$ and tended to be lower than those in the winter $(P=0.053$; Table 6$)$. When Gram status was replaced by Cult in the model, the concentration of $\mathrm{Hp}$ in the CNS group was about one-third that of the COLIF

Table 4. Geometric least squares means ${ }^{1}$ and $95 \%$ CI of measures of the innate immune response in milk from the affected quarter of cows with clinical mastitis by Gram staining characteristics of milk culture isolate accounting for systemic severity, parity group, DIM group, previous clinical mastitis occurrence, and season of the year

\begin{tabular}{|c|c|c|c|c|c|c|c|}
\hline Variable $^{2}$ & \multicolumn{3}{|c|}{ Gram-negative $(\mathrm{n}=83)$} & \multicolumn{3}{|c|}{ Gram-positive $(\mathrm{n}=64)$} & $P$-value \\
\hline $\mathrm{LBP}, \mu \mathrm{g} / \mathrm{mL}$ & 51.0 & 38.0 & 68.5 & 35.2 & 25.6 & 48.4 & 0.054 \\
\hline $\mathrm{BSA}, \mathrm{mg} / \mathrm{mL}$ & 6.08 & 4.89 & 7.56 & 3.85 & 3.04 & 4.88 & 0.002 \\
\hline $\mathrm{IL}-1 \beta, \mathrm{ng} / \mathrm{mL}$ & 4.35 & 3.33 & 5.68 & 2.55 & 1.91 & 3.41 & 0.003 \\
\hline IL-10, U/mL & 48.7 & 31.9 & 74.2 & 16.3 & 10.3 & 25.8 & $<0.001$ \\
\hline $\mathrm{LDH}, \mathrm{U} / \mathrm{L}$ & 1,558 & 1,210 & 2,007 & 1,501 & 1,141 & 1,975 & 0.820 \\
\hline
\end{tabular}

${ }^{1}$ Mean and CI obtained by taking the antilog of the $\log _{10}$ transformed data.

${ }^{2} \mathrm{LBP}=$ LPS-binding protein; Hp = haptoglobin; TGF = transforming growth factor; LDH = lactate dehydrogenase. 
Table 5. Geometric least squares means ${ }^{1}$ and $95 \%$ CI of measures of the innate immune response in milk from the affected quarter of cows with clinical mastitis by DIM group ${ }^{2}$ accounting for systemic severity, Gram staining characteristics of milk culture isolate, previous clinical mastitis occurrence, parity group, and season of the year

\begin{tabular}{|c|c|c|c|c|c|c|c|c|c|}
\hline \multirow{2}{*}{$\frac{\text { Variable }^{3}}{\mathrm{LBP}, \mu \mathrm{g} / \mathrm{mL}}$} & \multicolumn{3}{|c|}{ Early $(\mathrm{n}=38)$} & \multicolumn{3}{|c|}{ Mid $(\mathrm{n}=73)$} & \multicolumn{3}{|c|}{ Late $(\mathrm{n}=36)$} \\
\hline & $\frac{\text { Mean }}{63.3^{\mathrm{a}}}$ & 42.6 & 94.0 & $\frac{\text { Mean }}{52.9^{\mathrm{a}}}$ & 39.2 & 71.4 & $\frac{\text { Mean }}{27.5^{\mathrm{b}}}$ & 18.2 & 41.7 \\
\hline $\mathrm{BSA}, \mathrm{mg} / \mathrm{mL}$ & $3.98 \dagger$ & 2.97 & 5.35 & 4.26 & 3.40 & 5.33 & $6.54 \dagger$ & 4.80 & 8.90 \\
\hline 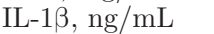 & 2.80 & 1.97 & 3.97 & 2.80 & 2.14 & 3.65 & 4.55 & 3.15 & 6.57 \\
\hline IL-10, U/mL & $17.7^{\mathrm{b}} \dagger$ & 9.92 & 31.6 & $36.1^{\mathrm{a}}$ & 23.2 & 56.0 & $35.4^{\mathrm{ab}_{\dagger}}$ & 19.3 & 65.0 \\
\hline TGF- $\beta$, ng/mL & 5.77 & 4.48 & 7.45 & 6.98 & 5.75 & 8.46 & 7.34 & 5.62 & 9.58 \\
\hline $\mathrm{LDH}, \mathrm{U} / \mathrm{L}$ & $1,267^{\mathrm{b}}$ & 900 & 1,784 & $2,080^{\mathrm{a}}$ & 1,604 & 2,696 & $1,678^{\mathrm{ab}}$ & 1,173 & 2,401 \\
\hline
\end{tabular}

${ }^{\mathrm{a}, \mathrm{b}}$ Means within a row with different superscripts differ $(P<0.048)$.

${ }^{1}$ Mean and CI obtained by taking the antilog of the $\log _{10}$ transformed data.

${ }^{2}$ Early $=1$ to 60 DIM; mid $=61$ to 150 DIM; late $=>150$ DIM.

${ }^{3} \mathrm{LBP}=$ LPS-binding protein; Hp = haptoglobin; TGF = transforming growth factor; LDH = lactate dehydrogenase.

$\dagger$ Means within a row differ $(P<0.080)$.

group $(P=0.046)$ and tended to be lower than the $E$. coli group $(P=0.093 ;$ Table 7$)$.

\section{BSA Concentration in Milk}

When cows were grouped by Gram status, the concentration of BSA in milk was associated with Gram status and season and tended toward an association with DIM group. The concentration of BSA was 1.6 times higher in the gram-negative versus the grampositive group $(P=0.002$; Table 4$)$. The late DIM group tended to have a higher concentration of BSA than those in the early group $(P=0.070$; Table 5$)$. The milk concentration of BSA was higher in cows with $\mathrm{CM}$ during the winter compared with those with $\mathrm{CM}$ in the summer $(P=0.013)$ or spring $(P=0.003$; Table $6)$. When Cult replaced Gram status in the model, the milk BSA concentration in the E. coli group was higher than the CNS group $(P=0.015)$ and tended to be higher than the ENS group $(P=0.053$; Table 7$)$.

\section{IL-1 $\beta$ Concentration in Milk}

When cows were grouped by Gram status, the concentration of IL-1 $1 \beta$ in milk was associated with systemic disease severity and Gram status. The concentration of IL-1 $\beta$ in the moderate to severe group was 1.6 times higher than the mild group $(P=0.005$; Table 3$)$. The concentration in the gram-negative group was more than 1.7 times greater than the gram-positive group $(P$

Table 6. Geometric least squares means ${ }^{1}$ and $95 \%$ CI of measures of the innate immune response in milk from the affected quarter of cows with clinical mastitis by season ${ }^{2}$ of the year accounting for systemic severity, Gram staining characteristics of milk culture isolates, parity group, DIM group, and previous clinical mastitis occurrence

\begin{tabular}{|c|c|c|c|c|c|c|c|c|c|c|c|c|}
\hline \multirow{2}{*}{$\frac{\text { Variable }^{3}}{\mathrm{LBP}, \mu \mathrm{g} / \mathrm{mL}}$} & \multicolumn{3}{|c|}{ Fall $(\mathrm{n}=22)$} & \multicolumn{3}{|c|}{ Winter $(\mathrm{n}=35)$} & \multicolumn{3}{|c|}{ Spring $(\mathrm{n}=54)$} & \multicolumn{3}{|c|}{ Summer $(\mathrm{n}=36)$} \\
\hline & $\frac{\text { Mean }}{36.1^{\mathrm{ab}}}$ & 22.1 & 58.8 & $\frac{\text { Mean }}{57.7^{\mathrm{a}}}$ & 38.8 & 85.8 & $\frac{\text { Mean }}{57.7^{\mathrm{a}}}$ & 40.7 & 81.6 & $\frac{\text { Mean }}{26.9^{\mathrm{b}}}$ & 17.7 & 41.0 \\
\hline $\mathrm{BSA}, \mathrm{mg} / \mathrm{mL}$ & $4.60^{\mathrm{ab}}$ & 3.20 & 6.60 & $7.49^{\mathrm{a}}$ & 5.59 & 10.1 & $3.93^{\mathrm{b}}$ & 3.04 & 5.09 & $4.05^{\mathrm{b}}$ & 2.97 & 5.53 \\
\hline $\mathrm{IL}-1 \beta, \mathrm{ng} / \mathrm{mL}$ & 3.43 & 2.21 & 5.34 & 4.55 & 3.18 & 6.52 & 2.80 & 2.04 & 3.84 & 2.81 & 1.92 & 4.11 \\
\hline IL-10, $\mathrm{U} / \mathrm{mL}$ & $44.4^{\mathrm{a}}$ & 22.1 & 89.3 & $48.0^{\mathrm{a}}$ & 27.2 & 84.7 & $28.7^{\mathrm{a}}$ & 17.5 & 47.3 & $10.3^{\mathrm{b}}$ & 5.64 & 18.8 \\
\hline $\mathrm{LDH}, \mathrm{U} / \mathrm{L}$ & $1,031^{\mathrm{c}}$ & 678 & 1,567 & $2,247^{\mathrm{a}}$ & 1,598 & 3,159 & $1,967^{\mathrm{ab}}$ & 1,459 & 2,652 & $1,201^{\mathrm{bc}}$ & 837 & 1,722 \\
\hline
\end{tabular}

${ }^{\mathrm{a}-\mathrm{c}}$ Means within a row with different superscripts differ $(P<0.046)$.

${ }^{1}$ Mean and CI obtained by taking the antilog of the $\log _{10}$ transformed data.

${ }^{2}$ Fall $=$ September to November; winter $=$ December to February; spring $=$ March to May; summer $=$ June to August.

${ }^{3} \mathrm{LBP}=$ LPS-binding protein; Hp = haptoglobin; TGF = transforming growth factor; LDH = lactate dehydrogenase.

$\dagger$ Means within a row differ $(P<0.098)$. 
Table 7. Geometric least squares means ${ }^{1}$ and $95 \%$ CI of measures of the innate immune response in milk from the affected quarter of cows with clinical mastitis by milk culture result ${ }^{2}$ accounting for systemic severity, parity group, DIM group, previous clinical mastitis occurrence, and season of the year

\begin{tabular}{|c|c|c|c|c|c|c|c|c|c|c|c|c|}
\hline \multirow{3}{*}{$\frac{\text { Variable }^{3}}{\mathrm{LBP}, \mu \mathrm{g} / \mathrm{mL}}$} & \multicolumn{3}{|c|}{ CNS $(\mathrm{n}=19)$} & \multicolumn{3}{|c|}{$\operatorname{ENS}(\mathrm{n}=45)$} & \multicolumn{3}{|c|}{ E. $\operatorname{coli}(\mathrm{n}=57)$} & \multicolumn{3}{|c|}{ COLIF $(\mathrm{n}=26)$} \\
\hline & \multirow{2}{*}{$\frac{\text { Mean }}{42.4}$} & \multicolumn{2}{|c|}{$95 \% \mathrm{CI}$} & \multirow{2}{*}{$\frac{\text { Mean }}{32.6}$} & \multicolumn{2}{|c|}{$95 \% \mathrm{CI}$} & \multirow{2}{*}{$\begin{array}{r}\text { Mean } \\
50.7\end{array}$} & \multicolumn{2}{|c|}{$95 \% \mathrm{CI}$} & \multirow{2}{*}{$\begin{array}{r}\text { Mean } \\
51.5\end{array}$} & \multicolumn{2}{|c|}{$95 \% \mathrm{CI}$} \\
\hline & & 24.7 & 73.0 & & 22.4 & 47.3 & & 36.3 & 70.8 & & 31.2 & 85 \\
\hline $\mathrm{BSA}, \mathrm{mg} / \mathrm{mL}$ & $3.22^{\mathrm{b}}$ & 2.16 & 4.81 & $4.09^{\mathrm{ab}} \dagger$ & 3.11 & 5.38 & $6.39^{\mathrm{a}} \dagger$ & 5.00 & 8.17 & $5.38^{\mathrm{ab}}$ & 3.72 & 7.79 \\
\hline 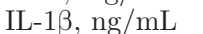 & $1.72^{\mathrm{b}}$ & 1.06 & 2.79 & $2.99^{\mathrm{ab}}$ & 2.14 & 4.17 & $4.50^{\mathrm{a}}$ & 3.34 & 6.06 & $4.04^{\mathrm{a}}$ & 2.58 & 6.32 \\
\hline $\mathrm{IL}-10, \mathrm{U} / \mathrm{mL}$ & $7.60^{\mathrm{c}} \dagger$ & 3.55 & 16.3 & $21.8^{\mathrm{bc}} \dagger$ & 12.9 & 36.9 & $53.6^{\mathrm{a}}$ & 33.6 & 85.6 & $39.0^{\mathrm{ab}}$ & 19.3 & 78.8 \\
\hline TGF- $\beta, n g / m L$ & 7.66 & 5.50 & 10.68 & 7.07 & 5.63 & 8.88 & 6.58 & 5.37 & 8.07 & 9.11 & 6.71 & 12.4 \\
\hline $\mathrm{LDH}, \mathrm{U} / \mathrm{L}$ & 1,148 & 722 & 1,825 & 1,682 & 1,223 & 2,314 & 1,562 & 1,175 & 2,078 & 1,567 & 1,021 & 2,404 \\
\hline
\end{tabular}

${ }^{\mathrm{a}-\mathrm{c}}$ Means within a row with different superscripts differ $(P<0.050)$.

${ }^{1}$ Mean and CI obtained by taking the antilog of the $\log _{10}$ transformed data.

${ }^{2} \mathrm{ENS}=$ environmental Streptococcus spp.; COLIF = gram-negative, non-Escherichia coli.

${ }^{3} \mathrm{LBP}=$ LPS-binding protein; $\mathrm{Hp}=$ haptoglobin; TGF = transforming growth factor; LDH = lactate dehydrogenase.

$\dagger$ Means within a row differ $(P<0.095)$.

$=0.005 ;$ Table 4). When Gram status was replaced by Cult in the model, the concentration of IL-1 $\beta$ in milk was more than 2 times higher in the $E$. $\operatorname{coli}(P=0.003)$ and COLIF $(P=0.034)$ compared with the CNS group (Table 7).

\section{IL-10 Concentration in Milk}

When cows were grouped by Gram status, the concentration of IL-10 in milk was associated with systemic disease severity, Gram status, DIM group, and season. The concentration of IL-10 in milk of the moderate to severe group was nearly 3 times greater than in the mild group $(P<0.001$; Table 3$)$. Similarly, the concentration was nearly 3 times higher in the gram-negative versus gram-positive group $(P<0.001$; Table 4$)$. The milk concentration of IL-10 was twice as high in the mid versus early DIM group $(P=0.019)$ and tended to be higher in the late versus early DIM group $(P=0.059$; Table 5). Compared with cows with CM during the summer, the concentration of IL-10 in milk was nearly 3 times higher in the spring $(P=0.028), 4.3$ times higher in the fall $(P=0.006)$, and 4.7 times higher in the winter $(P<0.001$; Table 6$)$. When Cult replaced Gram status in the model, the concentration of IL-10 in milk was 7 times higher in the $E$. coli $(P<0.001)$ group and 5 times higher in the COLIF $(P=0.006)$ group compared with the CNS group (Table 7). The concentration in the ENS group was approximately half that of the E. coli group $(P=0.035)$ and tended to be higher than in the CNS group $(P=0.082$; Table 7$)$.

\section{IL-12 Concentration in Milk}

When cows were grouped by Gram status, the concentration of IL-12 in milk was associated with sys- temic disease severity, DIM group, and parity group and tended toward an association with season. The concentration of IL-12 in milk of cows in the moderate to severe group was 2.2 times higher than of cows in the mild group ( $P=0.002$; Table 3$)$. The concentration of IL-12 was higher for third and greater parity cows (486 $\mathrm{U} / \mathrm{mL} ; 95 \%$ CI: 323, 731) compared with first (133 U/ $\mathrm{mL} ; 95 \%$ CI: 67,$265 ; P=0.003)$ and second $(210 \mathrm{U} /$ $\mathrm{mL} ; 95 \% \mathrm{CI}: 128,343 ; P=0.016)$ parity cows. The concentration in the late DIM group cows was nearly 4 times higher than that of the early DIM group $(P=$ 0.001 ) and tended to be higher in the mid versus early DIM group $(P=0.057$; Table 5$)$. Cows with CM in the summer tended to have a higher concentration of IL-12 in the milk compared with those with $\mathrm{CM}$ in the spring $(P=0.097$; Table 6$)$.

\section{TGF- $\alpha$ and TGF- $\beta$ Concentrations in Milk}

The concentrations of TGF- $\alpha$ and TGF- $\beta$ in milk were associated only with season. The concentration of TGF- $\alpha$ tended toward an association with Gram status (Table 4), and that of TGF- $\beta$ tended toward an association with previous CM occurrence. The concentration of TGF- $\alpha$ in the milk of cows with CM during the winter was 4 times greater and during the spring was 3.5 times greater than the concentration in cows with CM during the summer $(P<0.001$; Table 6$)$. The concentration of TGF- $\alpha$ in the milk of cows with $\mathrm{CM}$ during the winter was 3 times greater and during the spring was 2.6 times greater than the concentration in cows with $\mathrm{CM}$ during the fall $(P<0.001$; Table 6$)$. The concentration of TGF- $\beta$ in milk of cows with CM during the spring was 2 times greater $(P<0.001)$ and during the winter was 1.6 times greater $(P=0.034)$ than that 
of cows with CM during the summer (Table 6). Cows with CM during the fall had a TGF- $\beta$ concentration 1.8 times greater than that of cows with $\mathrm{CM}$ during the spring $(P=0.007$; Table 6$)$. The concentration of TGF- $\beta$ in milk tended to be higher in cows that had a previous CM episode $(8.05 \mathrm{ng} / \mathrm{mL} ; 95 \%$ CI: 6.34, 10.2) versus those that did not $(6.33 \mathrm{ng} / \mathrm{mL} ; 95 \%$ CI: 5.46 , 7.35; $P=0.073)$. When Cult replaced Gram status in the model, TGF- $\alpha$ concentration in the milk tended to be higher in cows of the $E$. coli versus CNS group $(P=$ 0.094; Table 7).

\section{LDH Activity in Milk}

The activity of LDH in the milk of cows with CM was associated with severity, DIM group, and season. The activity of $\mathrm{LDH}$ was 1.3 times greater in the moderate to severe versus the mild group $(P=0.014$; Table 3$)$. Cows in the mid DIM group had the highest activity of LDH in milk and was 1.6 times higher than that observed in the early group $(P=0.023$; Table 5$)$. The $\mathrm{LDH}$ activity in milk was highest in cows with CM during the winter and was 2.2 times greater than in cows with $\mathrm{CM}$ during the fall $(P=0.019)$ and 1.9 times greater than those with $\mathrm{CM}$ during the summer $(P=$ 0.037; Table 6). Cows with CM during the spring had 1.9 times higher LDH activity than those with CM during the fall $(P=0.045$; Table 6$)$.

\section{Detection of IFN- $y$, TNF- $\alpha$, and IL-8 in Milk}

A high proportion of milk samples, 67, 31, and 20\%, had undetectable levels of IFN- $\gamma$, TNF- $\alpha$, and IL- 8 , respectively. Detection of IFN- $\gamma$ in the milk of cows with CM was only associated with season, and the odds of detection were lower in the spring versus winter $(P$ $=0.005$; Table 8). Detection of TNF- $\alpha$ and IL- 8 in the milk of cows with CM was more likely in those with moderate to severe versus mild systemic disease and those with a gram-negative versus gram-positive milk culture result $(P<0.016$; Table 8$)$. Compared with that in cows with CM during the spring, detection of IL-8 in milk was more likely in cows with CM during the other seasons of the year $(P<0.038$; Table 8$)$.

\section{DISCUSSION}

To our knowledge, this is the largest study to date evaluating the milk concentrations of select APP and cytokines and the factors that may influence those levels in cows with naturally occurring CM caused by different pathogens. The frequency distribution of cows by milk culture result observed in the current study (Table 1) was similar to previous reports of cows with naturally occurring $\mathrm{CM}$, with a predominance of environmental mastitis pathogens typical of confinement herds that have successfully controlled contagious mastitis pathogens (Hogan et al., 1989; Bradley et al., 2007).

Large variation was observed among cows for the proteins evaluated in this study. One potential cause of variation not accounted for in the current study was the time postinfection (TPI) when cows were evaluated and samples collected. Experimental infection studies have identified a clear relationship between TPI and milk concentrations of innate immune response proteins (Bannerman, 2009). When studying naturally occurring CM, the TPI of sample collection is composed of 3 discrete periods: the time from infection to manifestation of clinical signs, from clinical signs to identification of CM, and from identification to sample collection. It is practically impossible to determine the first time period and the second is largely a function of the efficacy of CM screening in the study herds. The current study consisted of a single herd; therefore, the effect of CM screening should have been similar among cows. Ideally, samples would have been collected immediately after identification of CM. This would have been logistically difficult and costly if sample collection were performed by trained study personnel but easier if done by farm personnel. To ensure proper sample collection, handling, and clinical evaluation, we chose to have study personnel collect samples at 2 consistent times of the day. This likely resulted in increased variation in the time from identification to sample collection among the cows in the current study. We attempted to determine the length of this time interval; however, the time of identification was inconsistently recorded by farm personnel. These data were available for about half the cows in the study, and the average time between identification and sample collection was 6 $\mathrm{h}$ with a range of 1 to $12 \mathrm{~h}$ (data not shown). It seems unlikely that this sampling strategy would be biased toward any particular level of the factors being evaluated in the current study because all eligible cows were enrolled at each day and time a technician visited the farm. Nonetheless, failure to account for this potential confounding variable could have had an effect on the regression coefficients of the covariates evaluated in the current study and thus the associations identified with the proteins measured, particularly if TPI was highly correlated with one or more of the covariates and the measured protein concentrations (Frank, 2000). However, given the "statistical mechanics" of the linear model, failure to account for TPI would more likely result in a type II error (failure to identify an association) rather than a type I error (falsely declaring an association; Frank, 2000). Given this consideration, the variation observed between individual cows and the relative low 
Table 8. Factors associated with detectable cytokine concentrations in the milk of the affected quarter from cows with clinical mastitis in final logistic regression models with backward elimination

\begin{tabular}{|c|c|c|c|c|c|c|}
\hline \multirow{3}{*}{$\frac{\text { Cytokine }^{1}}{\text { IFN- } \gamma}$} & \multirow{3}{*}{$\begin{array}{l}\text { Factor }^{2} \\
\text { Season }\end{array}$} & \multirow[b]{2}{*}{$\%$ Det. $^{3}$} & \multicolumn{3}{|c|}{ Odds ratio $^{4}$} & \multirow[b]{2}{*}{$P$-value } \\
\hline & & & \multirow[t]{2}{*}{ Estimate } & \multicolumn{2}{|c|}{$95 \% \mathrm{CI}$} & \\
\hline & & & & & & 0.040 \\
\hline & Fall & 20 & 0.35 & 0.11 & 1.12 & 0.077 \\
\hline & Spring & 21 & 0.27 & 0.11 & 0.68 & 0.005 \\
\hline & Summer & 29 & 0.53 & 0.21 & 1.38 & 0.195 \\
\hline & Winter & 47 & Ref. $^{5}$ & & & \\
\hline \multirow[t]{6}{*}{ TNF- $\alpha$} & Severity & & & & & 0.002 \\
\hline & Mod./Sev. & 85 & 3.89 & 1.68 & 9.04 & \\
\hline & Mild & 59 & Ref. & & & \\
\hline & Gram status & & & & & 0.015 \\
\hline & GN & 78 & 2.55 & 1.20 & 5.38 & \\
\hline & GP & 58 & Ref. & & & \\
\hline \multirow[t]{11}{*}{ IL-8 } & Severity & & & & & 0.006 \\
\hline & Mod./Sev. & 88 & 4.55 & 1.54 & 13.5 & \\
\hline & Mild & 74 & Ref. & & & \\
\hline & Gram status & & & & & 0.003 \\
\hline & GN & 89 & 4.18 & 1.60 & 10.9 & \\
\hline & GP & 67 & Ref. & & & \\
\hline & Season & & & & & 0.003 \\
\hline & Fall & 77 & 4.32 & 1.09 & 17.1 & 0.037 \\
\hline & Summer & 87 & 8.46 & 2.04 & 35.1 & 0.003 \\
\hline & Winter & 78 & 6.50 & 1.76 & 24.0 & 0.005 \\
\hline & Spring & 56 & Ref. & & & \\
\hline
\end{tabular}

${ }^{1}$ Measured cytokines in which $>20 \%$ of samples had undetectable levels. Each cytokine was modeled separately. TNF- $\alpha=$ tumor necrosis factor- $\alpha$.

${ }^{2}$ Season: fall $=$ September to November, spring $=$ March to May, summer $=$ June to August, winter $=$ December to February; Severity: Mod./Sev. = moderate or severe systemic disease signs; Gram status: GN = gram-negative bacteria isolated on milk culture, $\mathrm{GP}=$ gram-positive bacteria isolated on milk culture.

${ }^{3} \%$ Det. $=$ percentage of samples with detectable levels of the cytokine measured. Detection limits: IFN- $\gamma:>90$ $\mathrm{pg} / \mathrm{mL}$; TNF- $\alpha$ : $>0.06 \mathrm{ng} / \mathrm{mL} ;$ IL-8: $>6.0 \mathrm{pg} / \mathrm{mL}$.

${ }^{4}$ Odds ratio for having detectable cytokine levels in the milk from a quarter affected with clinical mastitis.

${ }^{5}$ Ref. $=$ reference category.

sample size of some groups, failure to identify associations between the proteins and factors evaluated in the current study does not mean such an association does not exist. Nonetheless, in many instances no difference was detected between groups or the observed numerical difference was small, and the probability of falsely rejecting the null hypothesis was low.

Quarter level milk production was another factor not accounted for that could have influenced the concentration of the proteins evaluated in the current study. However, in 2 studies comparing Holstein and Jersey cattle, which had significant differences in milk production $(25.7 \pm 1.50$ and $18.9 \pm 1.50 \mathrm{~kg} / \mathrm{d}$, respectively; $P$ $=0.006)$, cytokine concentrations were almost identical in both following experimental IMI (Bannerman et al., 2008a,b).

The results of the current study suggest that several factors should be considered when designing studies to evaluate APP and cytokine concentrations during CM in dairy cattle. Systemic disease severity was associated with the concentrations of all proteins evaluated except for BSA, TGF- $\alpha$, and TGF- $\beta$. Geometric mean concen- trations of these proteins were 1.6 to 2.9 times greater in cows with moderate to severe disease compared with those with mild disease controlling for Gram status, DIM group, parity group, previous CM occurrence, and season (Table 3). The greatest differences were observed in the concentrations of Hp, IL-10, and IL-12. Similarly, the odds of detection of TNF- $\alpha$ and IL- 8 were greater in cows with moderate to severe versus mild systemic disease. These findings are consistent with a previous study of cows with naturally occurring coliform mastitis in which serum concentrations of TNF- $\alpha$, IL-1, and IL-6 were significantly higher in cows described as having severe clinical signs of systemic inflammatory response (Ohtsuka et al., 2001). The higher cytokine concentrations observed in the milk of cows in the moderate to severe group of the current study is consistent with a greater release of many of these proinflammatory mediators from the mammary gland to the vasculature where they exert systemic effects (Bannerman, 2009). Future studies of the innate immune response during $\mathrm{CM}$ in dairy cattle should include evaluation of systemic severity to reduce potential confounding. The systemic 
severity scoring system used in the current study has been previously shown to identify important differences in the pathophysiologic changes and outcomes of cows with acute coliform mastitis grouped by severity score (Wenz et al., 2001a,b). The differences identified in innate immune response between cows grouped by severity in the current study further validate severity scoring of CM of various etiologies based on systemic disease signs.

Sample collection occurred over an entire year; therefore, we evaluated the potential associations between the season of the year when a cow developed CM and the proteins evaluated. Season was associated with all the proteins evaluated except for IL-1 $\beta$ and IL-12. Except for TGF- $\beta$ and Hp, which were highest in the summer, concentrations were lowest during the summer and highest during the winter (Table 6). Detection of IFN- $\gamma$ and IL- 8 was also associated with season (Table 8). Thus, it appears that season influenced the immune response of cows with CM in the current study. Immune function has been shown to vary seasonally in many species independent of fluctuations in pathogen prevalence and could be associated with environmental conditions as well as photoperiod (Nelson et al., 2002). Studies manipulating the photoperiod of cows during the dry period suggest that a short-day photoperiod (SDPP) enhanced immune function associated with prolactin (PRL) sensitivity (Dahl, 2008). Cows exposed to SDPP had lower PRL but higher PRL receptor mRNA expression on lymphocytes compared with those exposed to a long-day photoperiod. Furthermore, SDPP cows showed enhanced peripheral blood neutrophil chemotaxis and lymphocyte proliferation compared with long-day photoperiod cows (Auchtung et al., 2004). Thus, the higher concentrations of many of the proteins evaluated in the current study during the winter months could be linked to enhanced immune function associated with SDPP. Improved neutrophil chemotaxis and lymphocyte proliferation may have resulted in an increased number of cytokine-producing leukocytes in the infected mammary gland. Indeed, in a study of cows without CM, mRNA expression of TNF- $\alpha$ and IL-1 $\beta$ was positively associated with higher SCC (Sarikaya et al., 2006). Unfortunately, the SCC of cows with CM in the current study was not evaluated.

Heat stress during the summer may have resulted in lower concentrations of many of the innate immune response proteins evaluated in the current study. Heat stress has been shown to decrease leukocyte migration into the mammary gland in response to chemotactic challenge (Elvinger et al., 1992). Furthermore, cows exposed to heat stress had higher plasma prolactin concentrations, reduced lymphocyte proliferation, and lower lymphocyte TNF- $\alpha$ production compared with cooled cows (do Amaral et al., 2010). Lymphocytes of heat-stressed cows also produced more suppressor of cytokine signaling (SOCS)-1 and SOCS-3 mRNA (do Amaral et al., 2010). The SOCS proteins are induced feedback inhibitors of cytokine signal transduction, and they suppress cytokine production by a variety of cell types including leukocytes (Yoshimura et al., 2007). It is interesting to note that SOCS pathways are suppressed in dry cows exposed to SDPP (Dahl, 2008). Taken together, these data suggest that the seasonal differences observed in the current study may be associated with environmental conditions and photoperiod effects on leukocyte function and SOCS expression. Further investigation is needed to confirm the results of the current study and better understand the relationship between season and the complex regulation of the immune response of cows with $\mathrm{CM}$ and the potential effect on the outcomes of CM.

The concentrations of LBP, IL-10, and IL-12 and LDH activity were associated with DIM group, controlling for severity, Gram status, parity group, previous $\mathrm{CM}$ occurrence, and season. For all of these proteins except LBP, the concentrations in the milk of cows experiencing CM during the first 60 DIM was lower than that of cows in the mid or late lactation groups (Table 5 ). Almost half of the 38 cows in the early DIM group were within $14 \mathrm{~d}$ of calving (data not shown) and these findings are consistent with the well-established immunosuppression observed in periparturient dairy cattle.

The Gram staining characteristics of the milk culture isolate were associated with the concentrations of $\mathrm{Hp}$, BSA, IL-1 $\beta$, and IL-10, controlling for severity, DIM group, parity group, previous CM occurrence, and season. The geometric mean concentrations of these proteins were 1.6 to 3.0 times greater in cows with a gram-negative compared with a gram-positive milk culture result (Table 4). Experimental infections have shown that the postinfection manifestation of clinical signs and induction of IL-1 $\beta$ and IL-10 was delayed and more prolonged in gram-positive compared with gram-negative infections, although the magnitude of the response was comparable (Bannerman, 2009). This suggests that the higher concentrations of IL- $1 \beta$ and IL-10 observed in the gram-negative group in the current study may have been because of a shorter TPI at the time of sampling compared with the gram-positive group. Alternatively, it is possible that a difference in the magnitude of the immune response between naturally occurring gram-negative and gram-positive infections exists that has not been observed in experimentally infected cows.

Grouping cows based on milk culture isolate was associated with the concentrations of $\mathrm{Hp}$, BSA, IL-1 $\beta$, and IL-10 in milk. Differences in the concentrations of 
these proteins were typically observed between cows in the CNS group and the E. coli or COLIF groups (Table 7). For all the proteins evaluated, the concentrations of the CNS group were numerically the lowest, whereas those in the E. coli or COLIF groups were the highest, and the ENS group was intermediate. As discussed earlier, the differences observed between individual gram-negative and gram-positive infected groups may reflect a difference in the time of sample collection. Alternatively, differences in the magnitude of the innate immune response may exist in cows with naturally occurring $\mathrm{CM}$ versus cows experimentally infected. Failure to detect significant differences in the proteins evaluated, where large numerical differences were observed in cows grouped based on milk culture result (Table 7) in the current study, may have been associated with low statistical power because of large variation between individual cows and the relatively small sample size of the groups.

The cytokine IFN- $\gamma$ was not detectable in a large proportion (67\%) of milk samples from cows in the current study. Logistic regression analysis identified season as a factor associated with the percentage of cows with detectable levels, and the percentage was nearly twice as high in the winter (47\%) compared with the other seasons (Table 8). Previous studies evaluating IFN- $\gamma$ following experimental infection with various pathogens (Bannerman 2009) and naturally occurring coliform mastitis (Hisaeda et al., 2001; Ohtsuka et al., 2001) did not report such a high proportion of cows with undetectable levels despite similar detection limits. Twenty-one cows with undetectable levels of IFN- $\gamma$ in the current study also had undetectable levels of TNF- $\alpha$ and IL-8. Most of these cows (76\%) had mild systemic disease and may have had a minimal inflammatory response to infection. Alternatively, that fact that $71 \%$ of cows with undetectable levels of IFN- $\gamma$, TNF- $\alpha$, and IL-8 had a gram-positive milk culture result (CNS and ENS) suggests they may have been sampled before detectable concentrations of these proteins had occurred (Bannerman 2009).

In conclusion, the current study provides a comprehensive report of the milk concentrations of commonly studied APP and cytokines associated with the innate immune response during naturally occurring $\mathrm{CM}$ and identifies factors that could influence those concentrations. Our results suggest that future studies of the role of these proteins in the pathogenesis of CM should control for systemic disease severity, season of the year (if appropriate), and stage of lactation through study design or inclusion of those factors as covariates in the analysis. More work is needed to better understand the relationship between season and immune function of cows with CM, including the potential role of photope- riod and SOCS expression. The results (Supplemental Table 1; http: \www.journalofdairyscience.org/) of this observational study have also provided data useful for sample size calculations when designing future studies to evaluate the innate immune response to $\mathrm{CM}$.

\section{REFERENCES}

Alluwaimi, A. M. 2004. The cytokines of bovine mammary gland: Prospects for diagnosis and therapy. Res. Vet. Sci. 77:211-222.

Auchtung, T. L., J. L. Salak-Johnson, D. E. Morin, C. C. Mallard, and G. E. Dahl. 2004. Effects of photoperiod during the dry period on cellular immune function of dairy cows. J. Dairy Sci. 87:36833689 .

Bannerman, D. D. 2009. Pathogen-dependent induction of cytokines and other soluble inflammatory mediators during intramammary infection of dairy cows. J. Anim. Sci. 87:10-25.

Bannerman, D. D., A. Chockalingam, M. J. Paape, and J. C. Hope. 2005. The bovine innate immune response during experimentallyinduced Pseudomonas aeruginosa mastitis. Vet. Immunol. Immunopathol. 107:201-215.

Bannerman, D. D., A. C. Kauf, M. J. Paape, H. R. Springer, and J. P. Goff. 2008b. Comparison of Holstein and Jersey innate immune responses to Escherichia coli intramammary infection. J. Dairy Sci. 91:2225-2235.

Bannerman, D. D., M. J. Paape, W. R. Hare, and E. J. Sung. 2003. Increased levels of LPS-binding protein in bovine blood and milk following bacterial lipopolysaccharide challenge. J. Dairy Sci. 86:3128-3137.

Bannerman, D. D., M. J. Paape, J. W. Lee, X. Zhao, J. C. Hope, and P. Rainard. 2004. Escherichia coli and Staphylococcus aureus elicit differential innate immune responses following intramammary infection. Clin. Diagn. Lab. Immunol. 11:463-472.

Bannerman, D. D., H. R. Springer, M. J. Paape, A. C. Kauf, and J. P. Goff. 2008a. Evaluation of breed-dependent differences in the innate immune responses of Holstein and Jersey cows to Staphylococcus aureus intramammary infection. J. Dairy Res. 75:291-301.

Bland, J. M., and D. G. Altman. 1996. Transformations, means, and confidence intervals. BMJ 312:1079.

Bradley, A. J., K. A. Leach, J. E. Breen, L. E. Green, and M. J. Green. 2007. Survey of the incidence and aetiology of mastitis on dairy farms in England and Wales. Vet. Rec. 160:253-257.

Burvenich, C., V. Van Merris, J. Mehrzad, A. Diez-Fraile, and L. Duchateau. 2003. Severity of E. coli mastitis is mainly determined by cow factors. Vet. Res. 34:521-564.

Chagunda, M. G. G., T. Larsen, M. Bjerring, and K. L. Ingvartsen. 2006. L-Lactate dehydrogenase and N-acetyl- $\beta$-D-glucosaminidase activities in bovine milk as indicators of non-specific mastitis. J. Dairy Res. 73:431-440.

Dahl, G. E. 2008. Effects of short day photoperiod on prolactin signaling in dry cows: A common mechanism among tissues and environments? J. Anim. Sci. 86:10-14.

do Amaral, B. C., E. E. Conner, S. Tao, J. Hayen, J. Bubolz, and G. E. Dahl. 2010. Heat stress abatement during the dry period influences prolactin signaling in lymphocytes. Domest. Anim. Endocrinol. 38:38-45.

Elliott, A. C., and J. S. Reisch. 2006. Implementing a multiple comparison test for proportions in a 2xc crosstabulation in SAS. Paper 204-31 in SUGI 31 Proc. http://www2.sas.com/proceedings/ sugi31/204-31.pdf Accessed Sep. 8, 2009.

Elvinger, F., R. P. Natzke, and P. J. Hansen. 1992. Interactions of heat stress and bovine somatotropin affecting physiology and immunology of lactating cows. J. Dairy Sci. 75:449-462.

Frank, K. A. 2000. Impact of a confounding variable on a regression coefficient. Sociol. Methods Res. 29:147-194.

Hisaeda, K., K. Hagiwara, J. Eguchi, H. Yamanaka, R. Kirisawa, and H. Iwai. 2001. Interferon- $\gamma$ and tumor necrosis factor- $\alpha$ levels in sera and whey of cattle with naturally occurring coliform mastitis. J. Vet. Med. Sci. 63:1009-1011. 
Hogan, J. S., K. L. Smith, K. H. Hoblet, P. S. Schoenberger, D. A. Todhunter, W. D. Hueston, D. E. Pritchard, G. L. Bowman, L. E. Heider, B. L. Brockett, and H. R. Conrad. 1989. Field survey of clinical mastitis in low somatic cell count herds. J. Dairy Sci. $72: 1547-1556$.

Hornef, M. W., M. J. Wick, M. Rhen, and S. Normark. 2002. Bacterial strategies for overcoming host innate and adaptive immune responses. Nat. Immunol. 3:1033-1040.

Lai, I. H., J. H. Tsao, Y. P. Lu, J. W. Lee, X. Zhao, F. L. Chien, and S. J. T. Mao. 2009. Neutrophils as one of the major haptoglobin sources in mastitis affected milk. Vet. Res. 40:17-29.

Lauzon, K., X. Zhao, and P. Lacasse. 2006. Deferoxamine reduces tissue damage during endotoxin-induced mastitis in dairy cows. J. Dairy Sci. 89:3846-3857.

Nelson, R. J., G. E. Demas, S. L. Klein, and L. J. Kriegsfeld. 2002. Seasonal Patterns of Stress, Immune Function, and Disease. Cambridge University Press, New York, NY.

Ohtsuka, H., K. Kudo, K. Mori, F. Nagai, A. Hatsugaya, M. Tajima, K. Tamura, F. Hoshi, M. Koiwa, and S. Kawamura. 2001. Acute phase response in naturally occurring coliform mastitis. J. Vet. Med. Sci. 63:675-678.

Rainard, P., and C. Riollet. 2006. Innate immunity of the bovine mammary gland. Vet. Res. 37:369-400.

Sarikaya, H., G. Schlamberger, H. H. D. Meyer, and R. M. Bruckmaier. 2006. Leukocyte populations and mRNA expression of inflammatory factors in quarter milk fractions at different somatic cell score levels in dairy cows. J. Dairy Sci. 89:2479-2486.
Seegers, H., C. Fourichon, and F. Beaudeau. 2003. Production effects related to mastitis and mastitis economics in dairy cattle herds. Vet. Res. 34:475-491.

Taniguchi, T. 1995. Cytokine signaling through nonreceptor protein tyrosine kinases. Science 268:251-255.

USDA. 2007. Dairy 2007, Part I: Reference of Dairy Cattle Health and Management Practices in the United States, 2007. USDA-APHISVS, CEAH, Fort Collins, CO, \#N480.1007.

Uthaisangsook, S., N. K. Day, S. L. Bahna, R. A. Good, and S. Haraguchi. 2002. Innate immunity and its role against infections. Ann. Allergy Asthma Immunol. 88:253-264.

Wenz, J. R., G. M. Barrington, F. B. Garry, R. P. Dinsmore, and R. J. Callan. 2001a. Use of systemic disease signs to assess disease severity in dairy cows with acute coliform mastitis. J. Am. Vet. Med. Assoc. 218:567-572.

Wenz, J. R., G. M. Barrington, F. B. Garry, K. D. McSweeney, R. P. Dinsmore, G. Goodell, and R. J. Callan. 2001b. Bacteremia associated with naturally occurring acute coliform mastitis in dairy cows. J. Am. Vet. Med. Assoc. 219:976-981.

Yoshimura, A., T. Naka, and M. Kubo. 2007. SOCS proteins, cytokine signaling and immune regulation. Nat. Rev. Immunol. 7:454465.

Zeng, R., B. J. Bequette, B. T. Vinyard, and D. D. Bannerman. 2009. Determination of milk and blood concentrations of lipopolysaccharide-binding protein in cows with naturally acquired subclinical and clinical mastitis. J. Dairy Sci. 92:980-989. 